\title{
MICROPROPAGAÇÃO COMOTÉCNICA DE REJUVENESCIMENTO EM MIRTILO (Vaccinium ashei Reade) CULTIVAR CLIMAX
}

\author{
Micropropagation as a rejuvenation technique in rabbiteye blueberry \\ (Vaccinium ashei Reade) cultivar climax
}

\author{
Márcia Wulff Schuch ${ }^{1}$, Cláudia Roberta Damiani ${ }^{2}$, Luciane Couto da Silva ${ }^{3}$, Alan Cristiano Erig ${ }^{4}$
}

\begin{abstract}
RESUMO
Objetivou-se com este experimento avaliar o rejuvenescimento do material vegetal através da técnica de micropropagação na produção de mudas de mirtilo, cv. Climax. Os tratamentos aplicados constituíram-se de dois tipos de citocininas (zeatina e 2iP), em quatro concentrações $\left(0 ; 2,5 ; 5,0\right.$ e 7,5 mg.L $\left.\mathrm{L}^{-1}\right)$ e duas fontes de explantes (plantas micropropagadas e plantas obtidas através da germinação de sementes in vitro). O delineamento experimental utilizado foi inteiramente casualizado, em esquema fatorial 2x4x2. Aos 60 dias após a instalação do experimento avaliou-se o número médio de brotos e de gemas por explante, o comprimento médio dos brotos e a taxa de multiplicação. Concluiu-se que plantas de mirtilo, micropropagadas na presença de citocinina e submetidas a sucessivas repicagens, demonstram elevada habilidade de rejuvenescimento in vitro do material adulto, podendo ser comparadas às plantas obtidas de semente, tanto na capacidade de emitir novas brotações, quanto no número de gemas e taxa de multiplicação.
\end{abstract}

Termos para indexação: Multiplicação in vitro, citocininas, Vaccinium ashei, Ericaceae.

\section{ABSTRACT}

This experiment was installed aiming to evaluate the plant rejuvenation capacity of rabbiteye blueberry seedlings cultivar Climax by using micropropagation technique. The treatments consisted of two cytokinin types (zeatin and 2iP), in four concentrations $\left(0 ; 2.5 ; 5.0\right.$ and $\left.7.5 \mathrm{mg} . \mathrm{L}^{-1}\right)$ and two sources of explants (micropropagated plants and plants from in vitro seeds germination). The experiment was carried out in a $2 \times 4 \times 2$ factorial arranged in a randomized complete design. After 60 days from experiment installation it was assessed the shoots average number and shoots average length, buds average number and the multiplication rate. In conclusion, the present results suggest that the micropropagated rabbiteye blueberry plants in the presence of cytokinin and submitted at successive cuttings showed a high in vitro rejuvenation ability of the adult material, which might be compared to the plants germinated in vitro, in the capacity of emitting new shoots as well as in the buds number and multiplication rate.

Index terms: In vitro Multiplication, Cytokinin, Vaccinium ashei, Ericaceae.

(Recebido em 8 de novembro de 2006 e aprovado em 23 de fevereiro de 2007)

\section{INTRODUÇÃo}

No sul do Brasil, a cultura do mirtilo vem sendo considerada uma nova alternativa na área de fruticultura, principalmente por suas propriedades nutracêuticas, alta rentabilidade, baixa utilização de insumos e facilidade de produção limpa, resguardando o ambiente e a segurança alimentar (SANTOS \& RASEIRA, 2002). A forma mais utilizada para a propagação dessa espécie no Brasil, é a estaquia, mas os resultados práticos são insatisfatórios variando com a cultivar (FACHINELLO et al., 1995). Mudas obtidas através de micropropagação são utilizadas no Uruguai (CASTILLO et al., 2004).
As plantas lenhosas, entre elas a maioria das frutíferas, sofrem mudanças consideráveis durante a transição da fase juvenil para a fase adulta, e segundo Wendling \& Xavier (2001) a maturação nelas é um assunto de extrema importância por causar, principalmente, variações na capacidade de propagação vegetativa, especialmente, no que se refere ao potencial de clonagem. Para a cultura de tecidos a consequiência mais significativa da utilização de explantes maduros é o declínio da competência de organogênese e outros processos de regeneração da planta in vitro (HUANG et al., 1990). O rejuvenescimento consiste na utilização de tratamentos ou técnicas que façam com que a planta passe de um estado maduro para um estado juvenil.

\footnotetext{
'Engenheira Agrônoma, Doutora, Professora - Departamento de Fitotecnia, Faculdade de Agronomia Eliseu Maciel/FAEM - Universidade Federal de Pelotas/UFPEL - Cx. P. 354 - 96010-900 - Pelotas, RS - marciaws@ufpel.tche.br - Pesquisadora CNPq

${ }^{2}$ Bióloga, Doutora - Departamento de Fitotecnia, Faculdade de Agronomia Eliseu Maciel/FAEM - Universidade Federal de Pelotas/UFPEL - Cx. P. 354 96010-900 - Pelotas, RS - claudami2004@yahoo.com.br - Bolsista DTI/CNPq

${ }^{3}$ Engenheira Agrônoma, Mestre - Departamento de Fitotecnia, Faculdade de Agronomia Eliseu Maciel/FAEM - Universidade Federal de Pelotas/UFPEL Cx. P. 354 - 96010-900 - Pelotas, RS - lucianecouto@yahoo.com.br

${ }^{4}$ Engenheiro Agrônomo, Doutor - Superintendência Federal de Agricultura no Rio Grande do Sul/UVAGRO - Ministério da Agricultura, Pecuária e Abastecimento/MAPA - 98995-000 - Porto Xavier, RS - alanerig@agricultura.gov.br
} 
A propagação sexuada é um método natural de promover o rejuvenescimento de partes maduras de plantas. Fachinello et al. (2005), afirmam que as principais limitações do uso comercial da propagação por sementes são a juvenilidade, o vigor elevado e a variabilidade genética, mesmo entre plantas originadas da mesma planta-matriz. Plantas propagadas por sementes apresentam características juvenis na região basal porque os meristemas mais próximos à base formaram-se em épocas mais próximas à germinação do que os das regiões terminais (HARTMANN et al., 1997).

Para o rejuvenescimento de espécies florestais, a micropropagação tem sido considerada a técnica mais eficiente, no entanto, seu uso ainda é limitado pela falta de domínio da técnica e pelos elevados custos envolvidos (WENDLING \& XAVIER, 2001). Andreu \& Marín (2005) compararam o tipo de planta (plantas propagadas por estaquia convencional e plantas produzidas através de micropropagação) como fonte de explantes para micropropagação e concluíram que explantes de portaenxertos de Prunus 'Adesoto101' retirados de plantas micropropagadas, têm maior capacidade propagativa do que aqueles retirados de mudas obtidas por estaquia, por causa do rejuvenescimento das plantas propagadas in vitro. Schuch \& Erig (2005) afirmam que uma das limitações do uso comercial da micropropagação, está no elevado período de juvenilidade após plantio no campo, causado pelo rejuvenescimento proporcionado pelas várias repicagens do material. Litwinczuk et al. (2005) estudaram o comportamento a campo de plantas de mirtilo do grupo highbush, cv. Herbert, comparando plantas propagadas através de estaquia com plantas micropropagadas e observaram que, mudas obtidas por estaquia tiveram um menor crescimento vegetativo, porém produziram frutos um ano antes daquelas obtidas por micropropagação.

Segundo Titon (2001), a dificuldade de enraizamento de certos clones na cultura do eucalipto através da estaquia é atribuída à maturação do material vegetal, levando à adoção de técnicas de reversão ao estado juvenil mediante a utilização da micropropagação.

Outro fator que causa o rejuvenescimento do material vegetal adulto, é a utilização de reguladores de crescimento, onde as concentrações internas e aplicações externas dessas substâncias estão relacionadas com características juvenis (ANDREU \& MARÍN, 2005). Erig $\&$ Schuch (2005), estabeleceram explantes retirados de plantas adultas de mirtilo, cultivar Flórida, in vitro, com a utilização de 2iP. Os mesmos autores, concluíram que a multiplicação in vitro de brotos de mirtilo cultivar Delite é favorecida com o uso de zeatina no meio de cultura. Silva
(2006) trabalhando com a cultivar Delite, também obteve melhores resultados com zeatina no meio de cultura, na fase de estabelecimento in vitro.

A capacidade de rejuvenescimento que a micropropagação proporciona, pode ser utilizada na produção de mudas de mirtilo inicialmente, utilizando-se a partir daí a microestaquia. Na microestaquia o laboratório de micropropagação funciona como local de rejuvenescimento das plantas para a produção de explantes que visam à formação do jardim microclonal que será o fornecedor de microestacas para o processo de produção de mudas (XAVIER \& WENDLING, 1998).

Objetivou-se neste trabalho avaliar o efeito da micropropagação in vitro como forma de indução de rejuvenescimento em plantas de mirtilo, comparando a capacidade de multiplicação in vitro de explantes obtidos de plantas em fase de multiplicação in vitro com explantes obtidos pela germinação de sementes, utilizando diferentes tipos e concentrações de citocininas.

\section{MATERIAL E MÉTODOS}

O trabalho foi realizado no Laboratório de Micropropagação de Plantas Frutíferas, Departamento de Fitotecnia, da Faculdade de Agronomia Eliseu Maciel (FAEM), na Universidade Federal de Pelotas (UFPel), Pelotas, RS.

Os tratamentos constituíram-se de duas diferentes citocininas utilizadas no meio de cultura (zeatina e 2iP), nas concentrações $\left(0 ; 2,5 ; 5,0\right.$ e 7,5 mg. $\left.\mathrm{L}^{-1}\right)$, onde foram utilizados como explantes segmentos caulinares de mirtilo, cv. Climax, com duas gemas, sem folhas e o ápice excisado, obtidos de plantas em fase de multiplicação in vitro no décimo subcultivo e de plantas obtidas através da germinação de sementes in vitro no primeiro subcultivo, no esquema fatorial $2 \times 4 \times 2$, totalizando 16 tratamentos. Foram utilizadas quatro repetições por tratamento, sendo cada repetição constituída de um frasco com cinco explantes. Após a inoculação, os frascos com os explantes foram mantidos em sala de crescimento com 16 horas de fotoperíodo, temperatura de $25 \pm 2^{\circ} \mathrm{C}$ e densidade de fluxo de fótons no período de luz de $42 \mu \mathrm{mol} . \mathrm{m}^{-2} . \mathrm{s}^{-1}$.

$\mathrm{O}$ meio de cultura basal, constituiu-se pelos sais do WPM - Wood Plant Medium (LLOYD \& MCCOWN, 1980), vitaminas de Gamborg et al. (1968), adicionado de 100 mg.L. $\mathrm{L}^{-1}$ de mio-inositol, 30 g.L $\mathrm{L}^{-1}$ de sacarose e 6 g.L $\mathrm{L}^{-1}$ de ágar (Vetec Química Fina Ltda, RJ-Brasil), e acrescido de citocinina (zeatina ou 2iP), em diferentes concentrações, conforme o tratamento. $\mathrm{O}$ pH foi ajustado para 5,2 antes da adição do ágar, e, posteriormente, os meios foram 
autoclavados à $121^{\circ} \mathrm{C}$ e 1,5 atm por 20 minutos. Foram utilizados frascos de $250 \mathrm{~mL}$, vedados com alumínio, contendo $30 \mathrm{~mL}$ de meio de cultura.

Aos 60 dias de cultivo, avaliou-se o número médio de brotos por explante, o número médio de gemas por explante, o comprimento médio dos brotos e a taxa de multiplicação; essa última obtida dividindo-se o número de gemas por explante obtido aos 60 dias de cultivo por dois (valor correspondente ao número de gemas por explante no início do experimento).

Os dados foram submetidos à análise de variância e as médias dos tratamentos comparadas estatisticamente pelo teste de Duncan, a 5\% de probabilidade. Os dados do número médio de brotos por explante, número médio de gemas por explante e da taxa de multiplicação foram transformados segundo $\sqrt{ }$; $\quad$ onde $\mathrm{x}$, corresponde ao número ou taxa obtidos.

\section{RESULTADOS E DISCUSSÃO}

Em relação ao número médio de brotos por explante, houve interação entre os fatores tipo de regulador de crescimento e concentração dos mesmos. Com o uso da zeatina houve maior número de brotações formadas em todas as concentrações utilizadas, sendo o número máximo $(15,71)$ obtido com 7,5 mg.L-1 (Figura 1). Com a utilização de $2 \mathrm{iP}$ os valores médios foram bem menores, não sendo superior a 2,29 brotos por explante.
Em Vaccinium corymbosum cv. Bluehaven, a utilização de zeatina no meio de proliferação promoveu maior número de brotações em comparação com o $2 \mathrm{iP}$ (ECCHER \& NOÈ, 1989). O efeito positivo da Zeatina no aumento do número de brotações em comparação com o uso de $2 \mathrm{iP}$, também foi verificado durante o estabelecimento in vitro de Vaccinium ashei, cv. Delite, por Silva (2006).

Quanto ao número médio de gemas formadas por brotação (Tabela 1), o tipo de citocinina utilizada afetou o resultado, obtendo-se o maior número médio de gemas $(5,93)$ com $2 \mathrm{iP}$ comparado ao uso de zeatina $(4,99)$. As brotações formadas em meio de cultura com zeatina, embora numerosas, apresentavam pequeno tamanho e menor número de gemas por brotação. Com relação às concentrações do regulador de crescimento e o tipo de explante, observou-se que na presença de regulador, em todas as concentrações, não houve diferenças significativas (Figura 2). No entanto, na ausência de regulador de crescimento, explantes advindos de plantas micropropagadas no décimo subcultivo, apresentaram maior número de gemas $(9,11)$ quando comparadas aos explantes originados de plantas obtidas por sementes $(5,75)$. Essa elevada capacidade de clonagem do material micropropagado na ausência de regulador, pode ser explicada pelo acúmulo endógeno e pela aplicação exógena de citocininas durante as sucessivas repicagens a

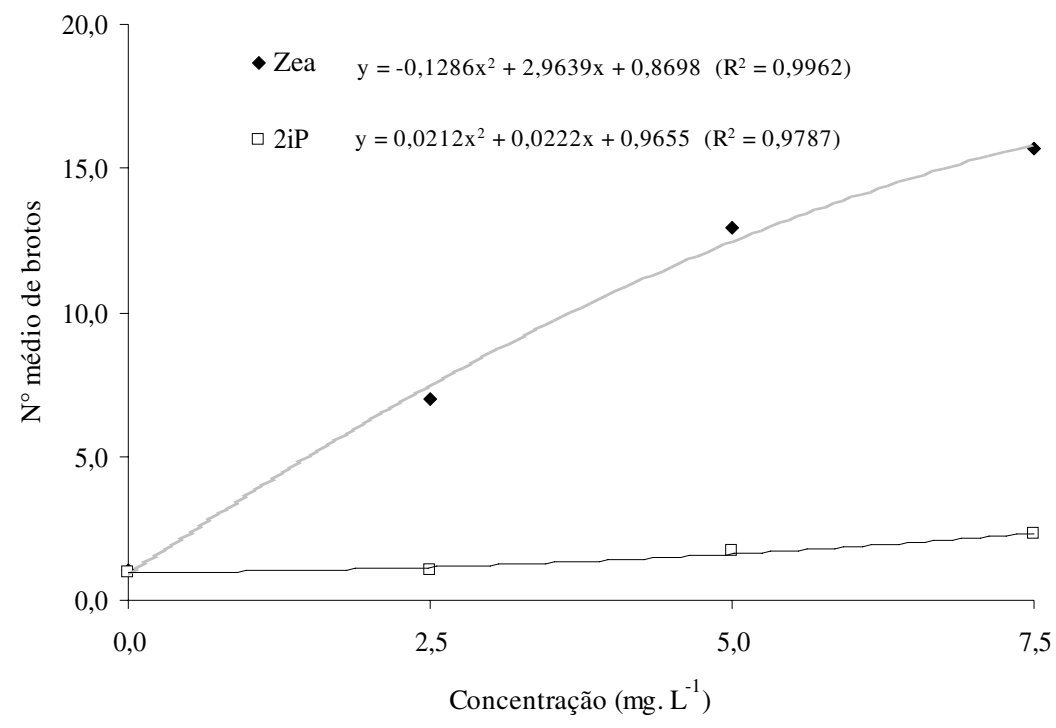

Figura 1 - Número médio de brotos de mirtilo (Vaccinium ashei Reade) cv. Climax, aos 60 dias de multiplicação in vitro em função do tipo de regulador de crescimento (Zeatina e $2 \mathrm{iP})$ e concentração dos reguladores $\left(0 ; 2,5 ; 5,0\right.$ e 7,5 mg. $\left.\mathrm{L}^{-1}\right)$. UFPEL, Pelotas-RS, 2006. 
Tabela 1 - Número médio das gemas de mirtilo (Vaccinium ashei Reade) cv. Clímax, aos 60 dias de multiplicação in vitro, em função do tipo de regulador de crescimento (Zeatina e 2iP). UFPEL, Pelotas - RS, 2006.

\begin{tabular}{cc}
\hline & $N^{\circ}$ Médio de Gemas* \\
\hline $2 \mathrm{iP}$ & $5,93 \mathrm{~A}$ \\
Zeatina & $4,99 \mathrm{~B}$ \\
\hline
\end{tabular}

* Médias seguidas pelas mesmas letras não diferem estatisticamente entre si, pelo teste de Duncan, ao nível de 5\% de probabilidade.

que as plantas foram submetidas e de acordo com Andreu \& Marín (2005), a aquisição de características juvenis do material adulto. Por outro lado, Litwinczuk et al. (2005), sugerem um número limitado de passagens ou de subcultivos durante a multiplicação, pois o rejuvenescimento excessivo, no caso de plantas frutíferas pode retardar a produção de frutos.

No comprimento médio das brotações, houve interação significativa entre o tipo de citocinina e concentração (Figura 3A) e tipo de planta e concentração do regulador de crescimento (Figura 3B). Plantas cultivadas em meio contendo $2 \mathrm{iP}$, independente da concentração, apresentaram brotações com maior comprimento quando comparadas àquelas cultivadas em zeatina. Por outro lado, as plantas micropropagadas diminuíram substancialmente o comprimento das brotações, com o aumento da concentração do regulador de crescimento, enquanto que as plantas provenientes de semente, mantiveram o comprimento das brotações constante, independentemente da concentração.

Para a taxa de multiplicação, houve interação entre tipo de planta e citocinina, onde explantes retirados de plantas micropropagadas cultivados em meio de cultura com zeatina tiveram uma maior taxa $(2,64)$, do que aqueles retirados de plantas produzidas através de sementes $(2,11)$, enquanto que com o uso de $2 \mathrm{iP}$ não houve diferença significativa entre a origem dos explantes, sendo observado 2,82 para plantas micropropagadas e 2,77 para plantas obtidas de semente. Ainda com relação à taxa de multiplicação (Figura 4), observou-se que na ausência de regulador de crescimento, explantes provenientes de plantas micropropagadas apresentam taxas superiores de multiplicação $(3,03)$, quando comparados a explantes provenientes de plantas obtidas de semente $(1,84)$. Quando tratados com reguladores, os tipos de explantes apresentam taxas semelhantes de multiplicação, não diferindo estatisticamente. Baseado nos dados obtidos, pode-se dizer que explantes retirados de plantas micropropagadas, demonstram maior capacidade de multiplicação quando comparados aos explantes retirados de plantas obtidas por semente, na ausência de reguladores, enfatizando assim, a importância do uso de citocininas no rejuvenescimento in vitro do material adulto. De acordo com Halupa (2002), a taxa de multiplicação é dependente do estado nutricional dos explantes e das condições ambientais, contudo o mesmo autor destaca a juvenilidade dos explantes, como fator determinante para a obtenção

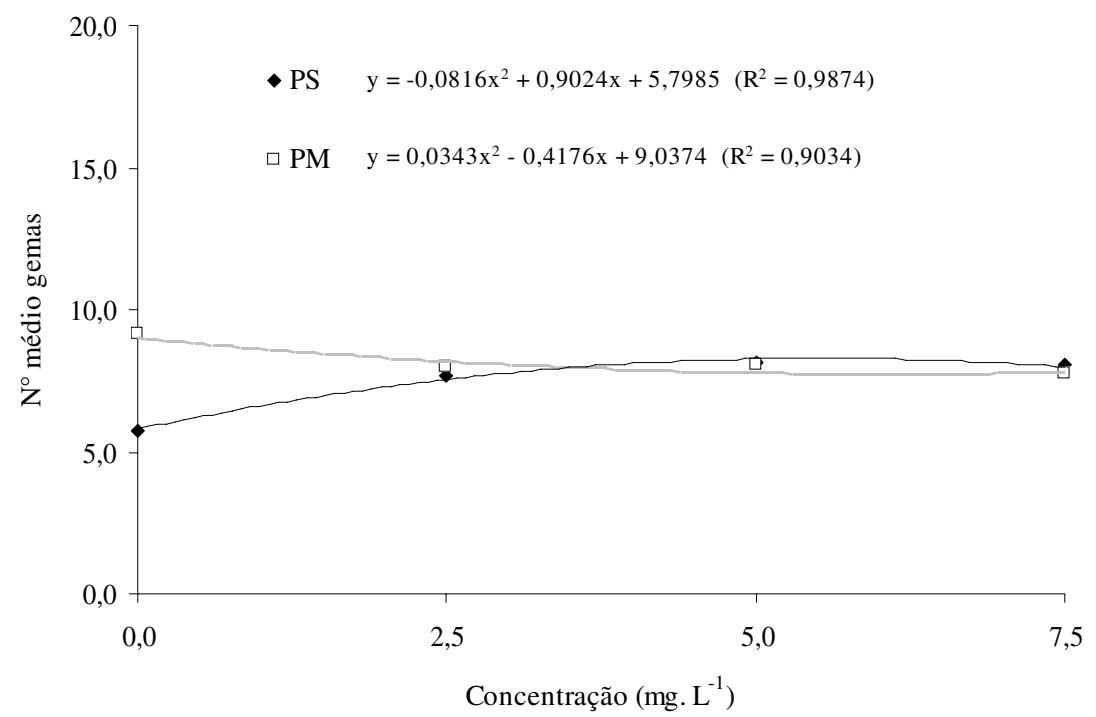

Figura 2 - Número médio das gemas de mirtilo (Vaccinium ashei Reade) cv. Clímax, aos 60 dias de multiplicação in vitro em função do tipo de planta (Planta Micropropagada = PM e Planta produzida de Semente $=$ PS) e concentração dos reguladores $\left(0 ; 2,5 ; 5,0\right.$ e 7,5 mg.L $\left.\mathrm{L}^{-1}\right)$. UFPEL, Pelotas - RS, 2006. 
de elevadas taxas de multiplicação e alongamento das brotações.

Quanto ao aspecto geral das brotações (Figura 5), explantes cultivados na presença de $2 \mathrm{iP}$ e retirados de plantas provenientes de semente, desenvolveram plantas mais alongadas e com folhas mais largas quando comparados àqueles provenientes de plantas micropropagadas. Explantes cultivados na presença de zeatina, de modo geral, desenvolvem plantas com entrenós mais curtos e folhas mais estreitas, no entanto apresentam grande número de brotações. $\mathrm{O}$ efeito positivo da zeatina na indução de brotações, também foi verificado por Eccher \& Noè (1989) na multiplicação in vitro de Vaccinium corymbosum. De acordo com esses autores, a zeatina apresenta menor fitoxidade quando comparada ao $2 \mathrm{iP}$, especialmente em concentrações elevadas. Por outro lado, na presença de zeatina, explantes de plantas provenientes de semente, apresentaram menor capacidade de emitir brotações em relação a explantes provenientes de plantas micropropagadas. Esses resultados, indicam que plantas submetidas à sucessivas repicagens durante a micropropagação, são rejuvenescidas pelo processo, e, adquirem uma alta capacidade de emitir novas brotações. Brand \& Lineberger (1992), quando compararam plantas provenientes de sementes e micropropagadas de bétula (Betulaceae), verificaram que morfologicamente não ocorrem diferenças significativas entre as mesmas. No entanto, os mesmos autores observaram que apesar do rejuvenescimento obtido durante a micropropagação in vitro de explantes retirados de plantas adultas, o nível de rejuvenescimento difere daquele encontrado nos explantes provenientes de plantas obtidas de semente.
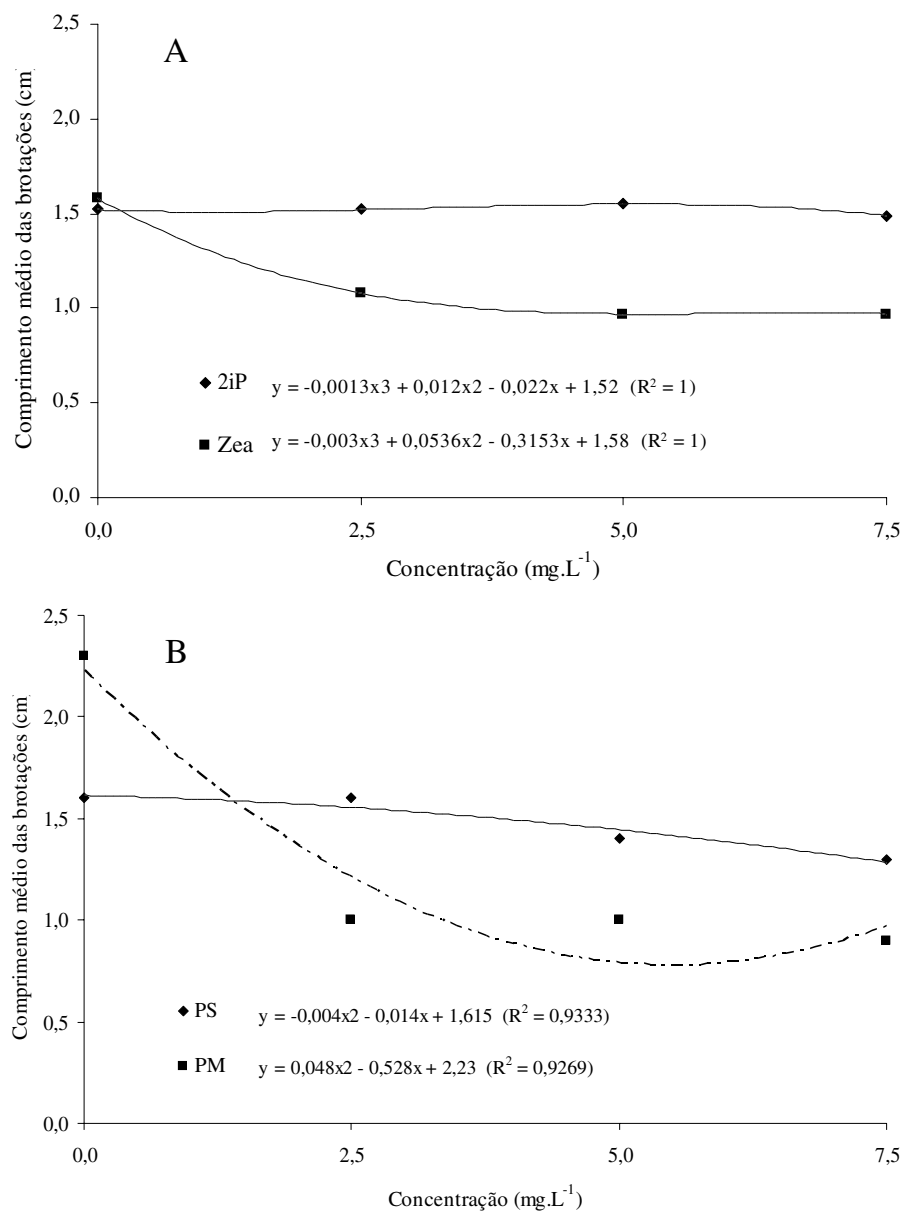

Figura 3 - Comprimento médio das brotações de mirtilo (Vaccinium ashei Reade) cv. Climax, aos 60 dias de multiplicação in vitro: (A) Tipo de regulador de crescimento (Zeatina e $2 \mathrm{iP})$ e concentração dos reguladores $\left(0 ; 2,5 ; 5,0\right.$ e 7,5 mg. $\left.\mathrm{L}^{-1}\right)$ e (B) Tipo de planta (Planta Micropropagada = PM e Planta produzida de Semente $=$ PS) e concentração dos reguladores (0; 2,5; 5,0 e 7,5 mg.L -1 $^{-1}$. UFPEL, Pelotas - RS, 2006. 


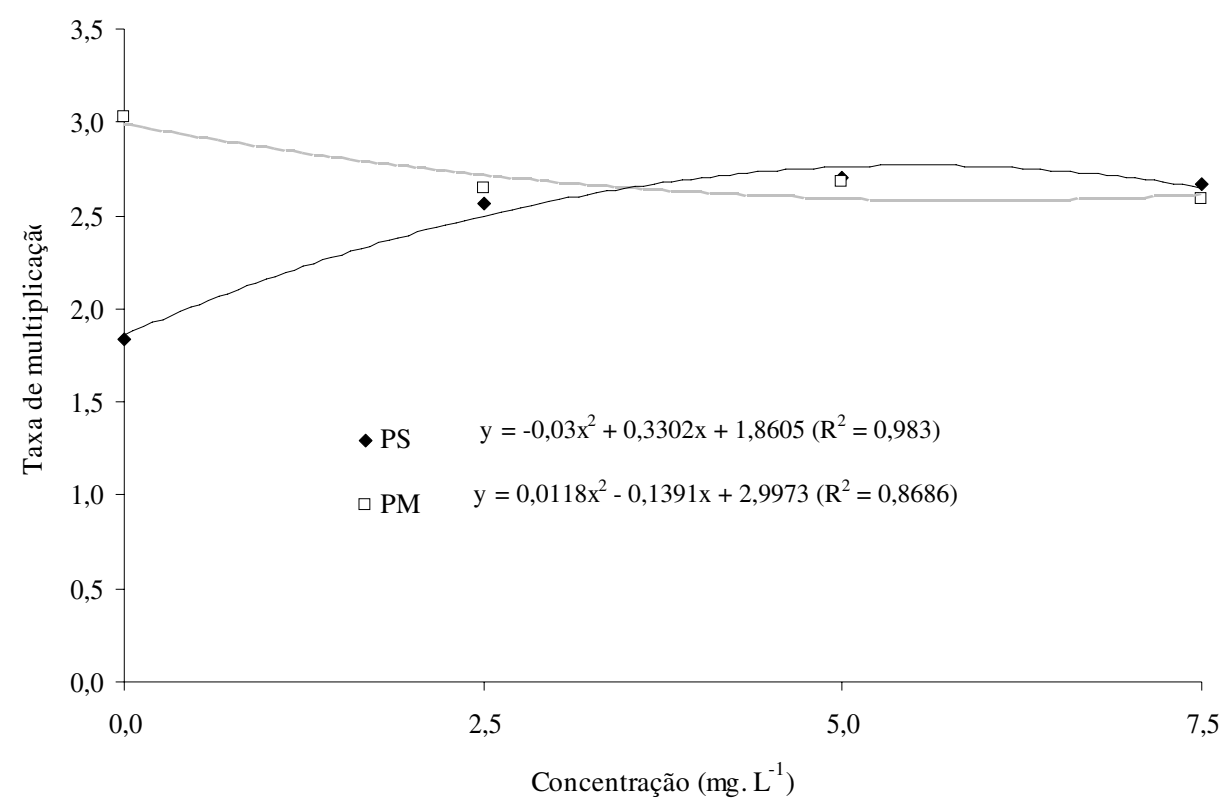

Figura 4 - Taxa de multiplicação de mirtilo (Vaccinium ashei Reade) cv. Climax, aos 60 dias de multiplicação in vitro em função do tipo de planta (Planta Micropropagada = PM e Planta produzida de Semente $=$ PS) e concentração dos reguladores $(0 ; 2,5 ; 5,0$ e 7,5 mg.L-1 $)$. UFPEL, Pelotas - RS, 2006.

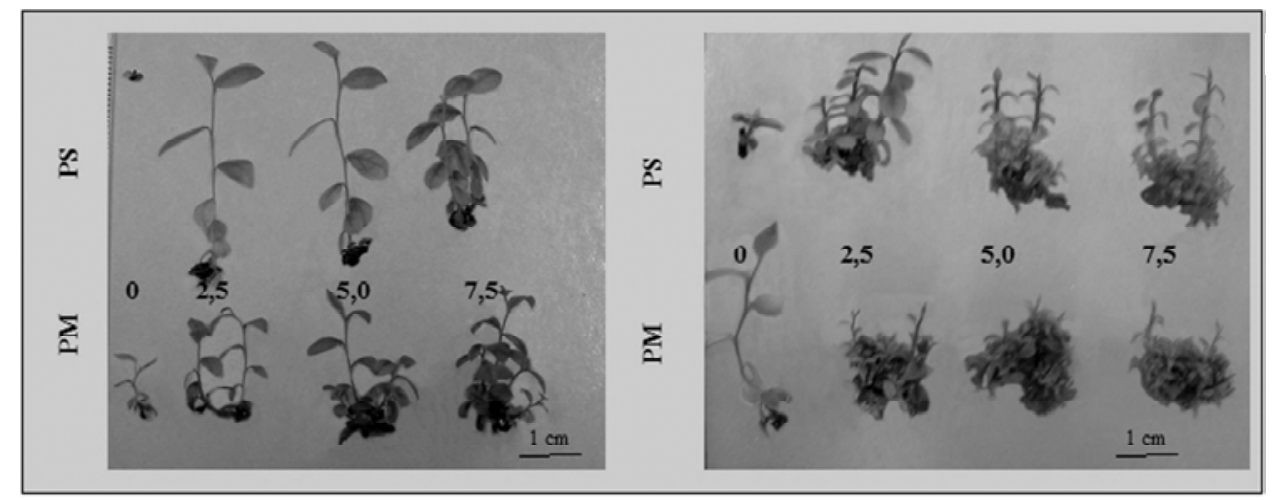

Figura 5 - Plantas micropropagadas de mirtilo (Vaccinium ashei Reade) cv. Climax, aos 60 dias de multiplicação in vitro, em função do tipo de citocinina (Zeatina e 2iP), nas concentrações 0; 2,5; 5,0 e 7,5 mg. $\mathrm{L}^{-1}$, e tipo de planta (Planta Micropropagada = PM e Planta produzida de Semente = PS). UFPEL, Pelotas - RS, 2006.

\section{CONCLUSÃO}

A micropropagação com sucessivas repicagens e cultivos na presença de citocinina, demonstra uma elevada habilidade de rejuvenescimento in vitro do material adulto, podendo ser comparada às plantas obtidas de semente, tanto na capacidade de emitir novas brotações, quanto ao número de gemas e taxa de multiplicação.

\section{AGRADECIMENTOS}

Este trabalho foi desenvolvido com o apoio do Ministério da Ciência e Tecnologia (MCT); Conselho Nacional de Desenvolvimento Científico e Tecnológico $(\mathrm{CNPq})$; Fundação de Amparo à Pesquisa do Estado do Rio Grande do Sul (FAPERGS). 


\section{REFERÊNCIAS BIBLIOGRÁFICAS}

ANDREU, P.; MARÍN, J. A. In vitro culture establishment and multiplication of the Prunus rootstock 'Adesoto 101' $(P$. insititia L.) as effected by the type of propagation of the donor plant and by the culture medium composition. Scientia Horticulturae, Amsterdam, v. 106, p. 258-267, 2005.

BRAND, M. H.; LINEBERGER, R. D. In vitro rejuvenation of betula (Betulaceae): morphological evaluation. American Journal of Botany, Saint Louis, v. 79, n. 6, p. 618-625, 1992.

CASTILLO, A.; CARRAU, J. S. F.; LEONI, C. Investigación en arandanos en Uruguay: propagación in vitro y evaluación de variedades por INIA. In: SIMPÓSIO NACIONAL DO MORANGO, 2.; ENCONTRO DE PEQUENAS FRUTAS E FRUTAS NATIVAS, 1., 2004, Pelotas, RS. Palestras e Resumos... Pelotas: Embrapa Clima Temperado, 2004. p. 225-228. (Documentos 124).

ECCHER, T.; NOÈ, N. Comparasion between 2iP and zeatin in the micropropagation of highbush blueberry (Vaccinium corymbosum). Acta Horticulturae (ISHS), Michigan, n. 241, p. 185-190, 1989.

ERIG, A. C.; SCHUCH, M. W. Estabelecimento in vitro de mirtilo a partir de segmentos nodais. Scientia Agraria, Curitiba, v. 6, n. 1/2, p. 91-96, 2005.

FACHINELLO, J. C.; HOFFMANN, A.; NACHTIGAL, J. C. (Eds.). Propagação de plantas frutíferas. Brasília, DF: Embrapa Informação Tecnológica, 2005. 221 p.

FACHINELLO, J. C.; HOFFMANN, A.; NACHTIGAL, J. C.; KERSTEN, E.; FORTES, G. R. de L. Propagação de plantas frutíferas de clima temperado. 2. ed. Pelotas: UFPel, 1995. $179 \mathrm{p}$.

GAMBORG, O. L.; MILLER, R.; OJIMA, K. Nutrient requirement of suspension cultures of soybean root cells. Experimental Cell Research, New York, v. 50, p. 151-158, 1968.

HALUPA, V. C. In vitro propagation of mature trees of Sorbus aucuparia L. and field performance of micropropagated trees. Journal of Forest Science, Praga, v. 48 , n. 12 , p. 529-535, 2002.
HARTMANN, H. T.; KESTER, D. E.; DAVIES JUNIOR, F. T.; GENEVE, R. L. Plant Propagation: principles and practices. 6. ed. New Jersey: Prentice-Hall, 1997. 770 p.

HUANG, L.; CHIU, D.; MURASHIGE, T.; GUNDY, R.; MAHDI, E. L. F. M.; NAGAI, K.; PLIEGO-ALFARRO, F. Rejuvenation of trees and other perennials for restoration of plant regeneration competence. In: TORRES, A. C.; CALDAS, L. S. Técnicas e aplicações da cultura de tecidos de plantas. Brasília, DF: ABCTP/Embrapa-CNPH, 1990.

LITWINCZUK, W.; SZCZERBA, G.; WRONA, D. Field performance of highbush blueberries (Vaccinium $\mathrm{x}$ corymbosum L.) cv. 'Herbert' propagated by cuttings and tissue culture. Scientia Horticulturae, Amsterdam, v. 106, n. 2, p. 162-169, 2005.

LLOYD, G.; McCOWN, B. Commercially feasible micropropagation of mountain laurel (Kalmia latifolia) by use of shoot-tip culture. Proceedings of the International Plant Propagation Society, Seattle, v. 30, p. 421-427, 1980.

SANTOS, A. M.; RASEIRA, M. C. B. A cultura do mirtilo. Pelotas: Embrapa Clima Temperado, 2002. 30 p.

SCHUCH, M. W.; ERIG, A. C. Micropropagação de plantas frutíferas. In: FACHINELLO, J. C.; HOFFMANN, A.; NACHTIGAL, J. C. Propagação de plantas frutíferas. Brasília, DF: Embrapa Informação Tecnológica, 2005. 221 p.

SILVA, L. C. da. Estabelecimento in vitro de cultivares de mirtilo (Vaccinium ashei Reade) para início da micropropagação. 2006. 54 f. Dissertação (Mestrado em Agronomia-Fruticultura de Clima Temperado) Universidade Federal de Pelotas, Pelotas, 2006.

TITON, M. Propagação clonal de Eucalyptus grandis por miniestaquia e microestaquia. 2001. 65 f. Dissertação (Mestrado em Ciência Florestal) - Universidade Federal de Viçosa, Viçosa, 2001.

XAVIER, A.; WENDLING, I. Miniestaquia na clonagem de Eucalyptus. Viçosa: SIF, 1998. 12 p. (Informativo técnico, 12).

WENDLING, I.; XAVIER, A. Gradiente de maturação e rejuvenescimento aplicado em espécies florestais. Floresta e Ambiente, Viçosa, v. 8, n. 1, p. 187-194, 2001. 